\title{
O discurso humorístico e a desconstrução de estereótipos sobre a mulher na
}

\section{produção televisiva}

\author{
The humorous discourse and the deconstruction of stereotypes about women in television
}

production

El discurso humorístico y la deconstrucción de estereotipos sobre las mujeres en la producción
televisiva

Recebido: 30/10/2021 | Revisado: 07/11/2021 | Aceito: 09/11/2021 | Publicado: 15/11/2021

\author{
José Domingos \\ ORCID: https://orcid.org/0000-0003-2765-1009 \\ Universidade Estadual da Paraíba, Brasil \\ E-mail: domingosuepb@gmail.com \\ Thiago Domingos da Silva Ferreira \\ ORCID: https://orcid.org/0000-0002-7912-9805 \\ Universidade Estadual da Paraíba, Brasil \\ E-mail:thiagodomingossf@gmail.com
}

\begin{abstract}
Resumo
Este artigo apresenta uma análise de piadas, cujo objeto discursivo é a mulher, com a finalidade de analisar discursivamente os efeitos de sentido dessa desconstrução no texto das piadas. Para alcançar este objetivo o trabalho está fundamentado na perspectiva da Análise do Discurso francesa, a partir das considerações apoiadas nas noções do discurso, formação discursiva, produção de sentido, estereótipos e a identidade da mulher. A pesquisa está baseada em um estudo bibliográfico de caráter descritivo, por meio da qual será realizada uma análise de cinco piadas veiculadas pelo programa. Verificou-se que as piadas são produzidas com base nos discursos machistas e estereotipados relacionados à identidade e ao papel social atribuído à mulher, a fim de produzir sentidos que desconstruam estas representações. É possível afirmar que o discurso humorístico veiculado pelo programa televisivo "Zorra" funciona no sentido de uma tentativa de desconstrução a respeito da identidade estereotipada da mulher, numa direção diferente dos programas desse gênero televisivo reafirmam estes estereótipos.
\end{abstract}

Palavras-chave: Discurso; Piada; Estereótipo.

\begin{abstract}
This article presents an analysis of jokes, whose discursive object is the woman, with the purpose of discursively analyzing the meaning effects of this deconstruction in the jokes' text. To achieve this purpose, the work is based on the perspective of French Discourse Analysis, from considerations supported by the notions of discourse, discursive formation, production of meaning, stereotypes and the identity of women. The research is based on a descriptive bibliographic study, through which an analysis of five jokes broadcast by the program will be carried out. It was found that jokes are produced based on sexist and stereotyped discourses related to the identity and social role assigned to women, in order to produce meanings that deconstruct these representations. It is possible to affirm that the humorous discourse conveyed by the television program "Zorra" works in the sense of an attempt to deconstruct the stereotyped identity of women, in a different direction than the programs of this television genre, reaffirm these stereotypes.
\end{abstract}

Keywords: Discourse; Joke; Stereotype.

\section{Resumen}

Este artículo presenta un análisis de los chistes, cuyo objeto discursivo es la mujer, con el propósito de analizar discursivamente los efectos de significado de esta deconstrucción en el texto de los chistes. Para lograr este objetivo, el trabajo se basa en la perspectiva del Análisis del Discurso Francés, a partir de consideraciones sustentadas en las nociones de discurso, formación discursiva, producción de sentido, estereotipos e identidad de la mujer. La investigación se basa en un estudio bibliográfico descriptivo, a través del cual se realizará un análisis de cinco chistes emitidos por el programa. Se encontró que los chistes se producen a partir de discursos sexistas y estereotipados relacionados con la identidad y el rol social asignado a la mujer, con el fin de producir significados que deconstruyan estas representaciones. Es posible afirmar que el discurso humorístico que transmite el programa de televisión "Zorra" funciona en el sentido de un intento de deconstruir la identidad estereotipada de la mujer, en una dirección diferente a los programas de este género televisivo, reafirma estos estereotipos.

Palabras clave: Discurso; Chiste; Estereotipo. 


\section{Introdução}

Historicamente, homens e mulheres sempre possuíram papéis sociais diferentes. Esse fato é uma consequência da forma pela qual a sociedade enxerga os sujeitos. Podemos perceber que através de muito esforço, as mulheres estão conquistando o seu espaço que antes lhes era negado. Um dos grandes responsáveis por esta transformação é o movimento feminista, que tem o seu início no século XIX, influenciado pela Revolução francesa, e as mudanças sociais que estavam ocorrendo na época. O feminismo, desde então, tem conseguindo atuar em diversas sociedades e culturas ao redor do mundo.

Tal movimento feminista defendeu e ainda defende a possibilidade às mulheres de que suas vozes fossem ouvidas e valorizadas e de se imporem contra o papel determinado pela sociedade para elas. Este movimento e as mudanças sociais vigentes geraram um conflito ideológico entre os sujeitos e a sociedade que, ainda, sustenta ideais, discursos e princípios machistas. Em alguns casos, são as próprias mulheres que protagonizam este conflito devido ao fato de serem educadas para que sustentem esta ideologia e as reproduza através de seus comportamentos e discursos. Uma das formas encontradas para expressar esse embate ideológico e social com relação ao machismo e o feminismo é através da linguagem, mais especificamente o discurso. Através da linguagem, o ser humano consegue difundir seus pensamentos e as ideologias presentes na sociedade em que acredita, tornando, então, o discurso como uma construção social. Por isso, concordamos com Brandão (2012) ao afirmar que,

A linguagem enquanto discurso não constitui um universo de signos que serve apenas como instrumento de comunicação ou suporte de pensamento; a linguagem enquanto discurso é interação, e um modo de produção social; ela não é neutra, inocente e nem natural, por isso o lugar privilegiado de manifestação da ideologia. (p.11)

O discurso apresenta em si não uma voz, mas diferentes vozes, as quais são constituídas por vozes conflitantes, mesmo no interior de uma mesma Formação Discursiva. O sujeito que enuncia apenas reproduz algo anteriormente dito por outra pessoa. As formações Discursivas se constituem através dos diferentes discursos ideológicos que se entrelaçam e são ditos levando em consideração as condições de produção sócio-históricas específicas.

Por outro lado, uma das formas da manifestação do discurso que abordam temas polêmicos é o humor que tem como uma de suas principais funções disfarçarem os medos e criticarem os problemas sociais. Conforme Gruda (2011) ao citar Justo (2006), "Muitos daqueles que fazem humor também se esquecem, por vezes, que o discurso humorístico tem, em seu caráter irreverente, uma crítica radical, essencialmente revolucionária [...]” (p.753).

Este tipo de discurso também é utilizado como uma maneira de amenizar ou disfarçar preconceitos. Devido a essa característica do humor de criticar a sociedade e utilizar-se do discurso preconceituoso, ele pode acabar ferindo alguns indivíduos, quando o motivo do riso é direcionado a um sujeito pertencente a um determinado grupo como, por exemplo, as mulheres, negros, portugueses, etc.

Por consequência a piada é a forma mais comum encontrada pelo discurso humorístico para materializar-se. As piadas que geralmente envolvem a mulher são produzidas com base em ideologias machistas, e através do discurso, materializam-se em o conflito das mudanças dos papéis sociais. Esse gênero discursivo pode ser encontrado nos mais diversos meios de comunicação e informação, um dos mais comuns e de maior alcance popular é nos programas humorísticos na televisão.

O programa "Zorra”, exibido pela rede Globo, também disponibilizado pela plataforma de streaming "Globoplay" e o site GSHOW, possui cunho humorístico e estar no ar desde 1999 o qual era exibido com o nome de "Zorra Total", mas em 2015, foi reformulado pela direção mudando também de nome. A reformulação do programa acarretou novas propostas de produção do humor, que se tornou mais crítico com relação às transformações político-sociais ocorridas no Brasil, e a situação da mulher não foi esquecida. A proposta das piadas com a mulher, como objeto central, trabalha a partir de estereótipos com o 
objetivo de desconstruí-los, tendo em vista as conquistas realizadas pelas mulheres na sociedade. Por isso, esse trabalho analisa as piadas exibidas pelo programa, a fim de se compreender o funcionamento do discurso na desconstrução destes estereótipos.

Partindo-se da ideia de que o programa "Zorra" propõe uma desconstrução do estereótipo a respeito da identidade feminina, considerando a reprodução de ideais machistas desse tipo de discurso encontrado nos programas "A Praça é Nossa" exibido pelo SBT, e a "Escolinha do Professor Raimundo: Nova geração", também exibida pela rede Globo. Buscamos discutir a seguinte questão: de que forma o discurso utilizado pelo programa "Zorra" funciona na desconstrução da identidade feminina, construída através dos discursos machistas, considerando os estereótipos historicamente reproduzidos por este gênero de entretenimento televisivo? Para responder a tal questionamento, este trabalho tem como objetivo principal analisar as piadas veiculadas na atração humorística "Zorra" que possuem como objeto discursivo a mulher, a fim de compreender como ocorre a desconstrução da identidade estereotipada da mulher como, por exemplo, a mulher submissa, fácil, ciumenta, etc. Partindo deste objetivo principal teremos os seguintes objetivos específicos: a) Descrever a produção de sentido nas piadas do humorístico que tematizam a mulher; b) Verificar como a memória discursiva se materializa no texto humorístico em análise.

Para a metodologia utilizada na produção desta pesquisa, utilizamos como corpus do trabalho as piadas presentes no programa "Zorra". Para a realização desta pesquisa, será adotada a metodologia qualitativa, pelo fato de que a compreensão e a explicação sobre alguns dos aspectos que aqui serão abordados não poderem ser traduzidas em números.

Situados nosso objeto e método de pesquisa, utilizaremos como base teórica para esta pesquisa a corrente teórica da Análise do Discurso francesa. O trabalho baseia-se nos estudos realizados pelos pesquisadores da Análise do Discurso como Brandão (2012), Bezerra (2017), Fernandes e Sá (2021), Joanilho e Joanilho (2012), Màziere (2007), Orlandi (1999 e 2010), Patti (2012), Pêcheux (1990) e Schneiders e Klein (2019). Além dos fundamentos da AD, discutiremos as noções de humor e estereótipos fundamentados em Freitas (2011), Grossi (2000), Gruda (2011), Justo (2006), Minois (2003), Pereira (2017), Possenti (2005), Rocha (2018) Simões (2004), Travaglia (1990) e Vale (2012 e 2015).

Em uma sociedade que tem mudado com relação ao papel social das mulheres, torna-se incoerente a permanência de tantos estereótipos com relação a estes sujeitos. Existem inúmeras pessoas que reproduzem discursos machistas e a valorização de estereótipos sobre a mulher.

Tendo em vista que a abordagem utilizada pelo programa "Zorra" na tentativa da desconstrução dos estereótipos em torno da identidade da mulher se tornou uma novidade para este tipo de programa, faz-se necessária a realização de pesquisas em Análise do Discurso, a fim de se aprofundar os estudos relacionados à temática.

Em suma, este trabalho está estruturado da seguinte forma: primeiramente, exporemos a respeito da fundamentação teórica utilizada na construção deste artigo, a Análise do Discurso e especificamente os conceitos de discurso, sujeito e ideologia, ademais a relação em torno da formação discursiva e a memória discursiva para o discurso. Em seguida iremos discorrer sobre o discurso humorístico presente na constituição das piadas, assim como também os estereótipos nele presentes. Após a explanação sobre o discurso humorístico iremos abordar a influência dos estudos de gênero para construção da identidade feminina e, por fim, a análise das piadas do programa "Zorra".

\section{Metodologia}

Para a realização desta pesquisa, foi adotada a metodologia qualitativa, pelo fato de que a compreensão e a explicação sobre alguns dos aspectos que aqui serão abordados não poderem ser traduzidas em números. A pesquisa se caracteriza como qualitativa, pois, conforme Bortoni-Ricardo (2008) e Pereira (2018) procura entender, interpretar fenômenos sociais inseridos em um contexto. Assim, no material selecionado e na análise dos trechos elencados, foram observados: a) quem diz; b) o que diz; c) para quem diz; d) quando diz; a fim de perceber as os valores discursivos, sintáticos, fonéticos, fonológicos e 
contextuais inerentes aos dizeres sobre a mulher. Serão analisadas quatro piadas presentes no programa, que possuam como tema a desconstrução dos estereótipos voltados para a mulher. As Análises aqui realizadas não serão compostas pela materialidade audiovisual do programa, e sim pelo texto escrito, considerando os objetivos propostos neste artigo.

O presente trabalho emprega também a técnica de pesquisa bibliográfica, pois através desse tipo de pesquisa serão levantados dados de referências teóricas, os quais possibilitam ao pesquisador conhecer mais sobre o assunto ao qual se propõe a trabalhar. A pesquisa bibliográfica é utilizada para investigações em torno das ideologias e as posições acerca de um problema. Com relação aos objetivos, a pesquisa se caracteriza como descritiva em que será proposto descrever como o discurso do humor, em seu caráter crítico e atrelado ao discurso feminista, é capaz de construir sentidos e verdades na sociedade. Pretende-se descrever os elementos presentes na sociedade como o discurso machista e feminista nas piadas, a fim de compreendê-los mais intensamente.

\section{Análise do Discurso: Alguns Conceitos}

No final dos anos de 1960, uma linha de pesquisa linguística ganha força através dos estudos de Michel Pêcheux. Seu objeto de estudo não estava focado na Língua ou apenas na enunciação, e sim no discurso. A corrente teórica da Análise do Discurso (AD) surgiu com base na necessidade de que os estudos linguísticos fossem voltados para o exterior do texto e para as condições de produção do discurso. Esta corrente linguística se propõe a fornecer os subsídios teóricos necessários para proporcionar uma maior reflexão a respeito dos sentidos produzidos pelos enunciados utilizados nas interações sociais. Como apontado por Brandão (2012) sobre a AD ela é,

Nascida da necessidade de superar o quadro teórico de uma linguística frasal e imanente que não dava conta do texto em toda sua complexidade, a análise de discurso volta-se para o "exterior" linguístico, procurando aprender como no linguístico inscrevem-se as condições sócio-históricos de produção. (p.103)

Na AD, a análise é realizada com base no enunciado, o qual se torna o dado para o estudo. Segundo Pêcheux (1990), a $\mathrm{AD}$ trabalha com enunciado a fim de interpretá-lo. Logo, "Todo enunciado, toda sequência de enunciados é, pois, linguisticamente descritível como uma série (...) de pontos de deriva possíveis, oferecendo um lugar à interpretação. É nesse espaço que pretende trabalhar a análise de discurso.” (p.53-54). A proposta realizada por Pêcheux é a de procurar realizar uma interpretação que possibilite a procura de sentido no texto, uma relação entre o enunciado e a sociedade, o que para ele se torna uma relação dialética do texto.

Com a finalidade que a interpretação funcione não se deve procurar qualquer enunciado constituído por palavras e que não possuem sentido, sentido esse que deve estar associado a algum fato sócio-histórico, como apontado por Joanilho A. e Joanilho M. (2012), por isso, “[...] As análises devem mostrar que o sentido se produz a partir de uma base estruturante, isto é, iniciando pela palavra, o átomo do discurso. Mas não qualquer palavra, ou melhor, qualquer palavra posta em movimento. (p.29)".

Faz-se necessário estudar o enunciado levando em consideração a estrutura e como ela foi construída baseada na influência histórica e social, tendo como base um enunciado que possua sentido e uma razão que a levou a ser proferida. Segundo Mazière (2007) "ela (AD) não separa o enunciado nem de sua estrutura linguística, nem de suas condições de produção, de suas condições históricas e políticas, nem das interações subjetivas. Ela dá suas próprias regras de leituras, visando permitir uma interpretação." (p.13). Nesse sentido as análises devem procurar o sentido que os enunciados produzem a partir da estruturação das palavras realizadas pelo sujeito, ou seja, a forma que ele disse algo e as condições de produção que o levou a proferir algo de tal forma e não apenas as frases e orações produzidas de forma descontextualizadas. O que para Orlandi (1999), 
Os dizeres não são, como, dissemos, apenas mensagens a serem decodificadas. São efeitos de sentidos que são produzidos em condições determinadas e que estão de alguma forma presentes no modo como se diz, deixando vestígios que o analista do discurso tem de aprender. São pistas que ele aprende a seguir para compreender os sentidos aí produzidos, pondo em relação ao dizer com sua exterioridade, suas condições de produção. (p.30)

Outra questão referente à produção do enunciado refere-se àquele que enuncia, o sujeito. $\mathrm{Na} \mathrm{AD}$, o discurso necessita do sujeito, assim como o sujeito necessita do discurso. Ambos se complementam, pois é através do discurso que o sujeito expressa a ideologia com a qual se identifica e defende utilizando uma determinada formação discursiva. "Para a $\mathrm{AD}$, não há discurso sem sujeito e sujeito sem ideologia. O sujeito, para a AD, é constituído através da interpelação ideológica." (Klein \& Schneiders, 2019, p. 207).

Para realização das pesquisas em $\mathrm{AD}$, o enunciado é de suma importância, mas deve se levar em consideração também quem enuncia. A noção de sujeito trabalhada é o de não-sujeito, o sujeito não é determinado como aquele que enuncia, mas é determinado pela estrutura que o texto possui. O sujeito não é o autor de um enunciado em si, ele é "atravessado" por um ou mais discursos, o que para a AD de 1969 o sujeito torna-se apenas um vetor, um transmissor pelo qual os discursos são enunciados. O sujeito na realidade é constituído, por assim dizer, por outros fatores referentes à sociedade e à história, ele carrega em seu discurso outras vozes, o que significa que ele não é realmente o responsável pela fonte de seu dizer. Concordamos com Patti (2012) ao afirmar que,

[...] Dessa forma, ele enuncia na ilusão de escolher e definir o que diz, de controlar os sentidos, mas não sabe que, antes, ele é determinado tanto por seu lugar subjetivo possível naquele determinado momento de sua enunciação quanto por sua exterioridade, pela história que o atravessa, o que faz com que ele só tenha acesso a parte do que diz. Assim, dividido, o sujeito não tem como controlar os sentidos como um todo, pois eles podem sempre vir-a-serem outro na relação com o outro, nas variações do tempo e do espaço em que ocorrem as enunciações[...] (p.18).

Para a AD, o discurso é estudado como um produto construído de forma coletiva, ou seja, o discurso não é algo formulado pelo sujeito isolado, e sim algo constituído pela sociedade historicamente, sobrevivendo através da memória social dos sujeitos do discurso. Os enunciados expressos, através dos meios de comunicação e dos mais diversos gêneros discursivos auxiliam, na perpetuação de ideias e ideologias construídas socialmente.

A AD possibilita ao pesquisador percorrer por outros campos científicos além da linguística, como a Psicologia e Sociologia para tornar possível a compreensão das condições de produção do discurso. Conforme Bezerra e Domingos (2017), “A Análise do Discurso, pelo seu caráter interdisciplinar, nos permite refletir e analisar sobre outros campos de conhecimento, a partir das teorias sobre a produção dos sentidos sociais." (p. 27). A produção de sentido no discurso só se torna possível através do interdiscurso, o qual está ligado à memória discursiva presente na sociedade. Segundo Orlandi (1999), “As palavras falam com outras palavras. Toda palavra é sempre parte de um discurso. E todo discurso se delineia na relação com outros: dizeres presentes e dizeres que se alojam na memória.” (p.43). Os enunciados que produzimos possuem um objetivo e função, através dela produzimos e reproduzimos discursos baseados com outros que foram e estão sendo reproduzidos socialmente.

\section{Memória Discursiva e a Formação Discursiva}

A concepção de memória, durante muito tempo, foi enxergada como algo ligado a uma função psicológica humana que seria responsável por armazenar as experiências vivenciadas por um indivíduo, mas só entre o século XIX e o século XX veio a ser estudado outro tipo de conceito para memória, uma construída socialmente. Um dos primeiros teóricos a trabalhar com a concepção de uma memória social foi o teórico Henri Bergson, que, em suas pesquisas, procurou relacionar a memória individual e a memória social. Uma das formas que essa memória pode se materializar é através do discurso, o que a Análise do Discurso define como memória discursiva. A memória discursiva torna-se uma ferramenta para formulação de um 
enunciado pelo simples fato de que ele está sendo baseado em algo que já foi dito anteriormente, ou seja, "A memória discursiva ou interdiscurso diz respeito ao fato de que todo dizer está ancorado em outros dizeres [...]" (Klein \& Schneiders, 2019, p. 207).

É através da utilização deste tipo de memória que podemos ser capazes de produzir textos que possibilitem o uso de implícitos que auxiliam na formação de inferências a respeito de algum fato ou ideal que o emissor acredite. Como apontado por Bezerra e Domingos (2017), ao citar Pêcheux (1999),

Aquilo que face a um texto que surge como acontecimento a ser lido, vem restabelecer os "implícitos" (quer dizer, mais tecnicamente, os pré-construídos, elementos citados e relatados, discursos transversos etc.) de que sua leitura necessita: a condição do legível em relação ao próprio legível. (p.27).

A memória discursiva é uma parte constituinte de qualquer discurso, através dela podemos perceber outras vozes que constituem os enunciados produzidos. Essas outras vozes são atribuídas ao interdiscurso por apresentarem outros discursos já produzidos ao longo da história, ou seja, "[...] algo fala antes, em outro lugar e independentemente [...] É o já dito que constitui todo dizer" (Orlandi, 2010, p. 21). Através da memória, um sujeito pode reproduzir um enunciado que seja capaz de perpetuar um preconceito e um estereótipo que já havia se estabelecido anteriormente.

A memória discursiva, presente nos discursos, acaba por ser responsável no estabelecimento da ordem social, pois os enunciados são formulados com base em uma ideologia compartilhada socialmente. Quando alguém não concorda com algo imposto socialmente ele acaba por ser excluído pela sociedade como, por exemplo, no caso das feministas que, ao reagirem contra os discursos machistas sustentados pelo patriarcado, acabam sendo colocadas de lado pela sociedade. Ao citar um comentário feito por Foucault com relação ao discurso como ordenador social, Simões (2004) afirma que,

O discurso passa a ser reconhecido então como um ordenador do sistema social. Vale ressaltar que ordenar essa sociedade significa enquadrar, e aqueles que não se enquadram em determinado conceito social, e que não refletem o discurso dominante, tornam-se marginais, não tomando a palavra no sentido de bandido, mas sim daqueles que vivem à margem da sociedade e do discurso/pensamento vigente da maioria da população, sendo portanto execrados ou não reconhecidos enquanto cidadãos. (p.2)

Como podemos observar, os discursos não podem ser enxergados como algo puramente novo ou inédito, com relação às ideias nele presentes. Os discursos apresentam em seu interior outros discursos construídos socialmente. Essa relação entre esses discursos é chamada de interdiscurso. $\mathrm{O}$ interdiscurso ocorre quando um discurso incorpora os discursos que circulam pela sociedade e acabam por serem assimilados pelo sujeito e que, em algum momento, ao enunciar o seu discurso, acaba por também promover os discursos que ouviu ao seu redor. Concordamos com Brandão (2012) ao citar Courtine e Marandine (1981) ao afirmar que

O interdiscurso consiste em um processo de reconfiguração incessante no qual uma formação é conduzida [...] a incorporar elementos pré-construídos produzidos no exterior dela própria; a produzir sua redefinição e seu retorno, a suscitar igualmente a lembrança de seus próprios elementos, a organizar a sua repetição, mas também a provocar eventualmente seu apagamento, o esquecimento ou mesmo a denegação (p.91)

Levando em consideração que tudo aquilo que é dito na sociedade tem como base algo já dito anteriormente, as formações dos enunciados também serão baseadas em formações ideológicas já existentes. Os enunciados produzidos pelos sujeitos são formulados com base em inúmeros discursos que se constroem no interior das Formações Discursivas (FD), levando em conta a situação sócio-histórica, na qual o sujeito está inserido para determinar aquilo que será enunciado. A FD 
faz alusão ao que se pode dizer levando em consideração o momento sóciohistórico vivenciado pelo sujeito, e as condições de produção possíveis do momento da enunciação. Conforme Fernandes e Sá (2021),

Uma formação discursiva caracteriza-se pela existência de um conjunto semelhante de objetos e enunciados que os descrevem, pela possibilidade de explicitar como cada objeto do discurso tem, nela, o seu lugar e sua regra de aparição, e como as estratégias que a engendram derivam de um mesmo jogo de relações. (p.59)

Orlandi (1999) define a FD como "[...] aquilo que numa formação ideológica dada - ou seja, a partir de uma posição dada em uma conjuntura sócio-histórica dada - determina o que pode e deve ser dito.” (p.43). Nela também estão representadas as formações ideológicas. Essas formações ideológicas também são utilizadas na formulação dos enunciados que constituem o discurso humorístico.

As FDs são formuladas com base em ideologias presentes no círculo social no qual os indivíduos estão integrados, por isso essas formações às vezes acabam se contradizendo. Uma FD é constituída por discursos diversos, um tema como identidade da mulher acaba por gerar inúmeras tensões devido aos diferentes ideais defendidos pelos sujeitos. Conforme Fernandes e Sá (2021), “[...] uma formação discursiva nunca é homogênea, é sempre constituída por diferentes discursos. Um mesmo tema, ao ser colocado em evidência, é objeto de conflitos, de tensão, face às diferentes posições ocupadas por sujeitos que se opõem, contestam-se.” (p.56). Como poderá ser observado neste trabalho, o discurso sobre as mulheres nas piadas vinculadas ao programa Zorra emergem numa FD que entra em conflito com aquelas em que historicamente circularam discursos machistas e estereotipados sobre estes sujeitos como, por exemplo, o da ex mulher ciumenta e o papel social da mulher.

\section{Discurso Humorístico e Estereótipos}

O humor é algo há muito tempo existente, estando presente deste os primórdios da humanidade. Devido este possuir como um de seus princípios básicos e fundamentais o trabalho com o riso e a zombaria, ele nem sempre foi bem aceito, podemos verificar este feito na Arte poética de Aristóteles, no qual realiza, então, uma diferenciação entre os gêneros tragédia e comédia, tratando o segundo como um gênero inferior. O discurso humorístico existente na antiguidade clássica era utilizado em encenações de peças teatrais. Tal atitude deve-se ao fato de que Aristóteles defendia que a tragédia em si era superior à comédia pelo fato de que esta era capaz de promover uma elevação moral através da catarse, enquanto aquela provocava o riso através da representação do ridículo.

O discurso humorístico tem como um dos seus principais objetivos provocar o riso ou ao menos provocar um sorriso através de atos e de enunciados que se tornem divertidos e contagiantes. É através do humor que o ser humano procura uma forma para tentar fugir e escapar da dura realidade que enfrenta em sua vida, como diz um velho ditado popular bastante conhecido diz que "é melhor rir do que chorar". Portanto, o humor não só é capaz de provocar o riso, mas também é utilizado para amenizar as dificuldades que enfrentamos em nosso cotidiano na sociedade, como é afirmado por Minois (2003),

O riso não seria, de fato, a resposta apropriada? Se realmente nada tem sentido, o escárnio não seria a única atitude "razoável"? O riso não é o único meio de nos fazer suportar a existência a partir do momento em que nenhuma explicação parece convincente? O humor não é o valor supremo que permite aceitar sem compreender, agir sem desconfiar assumir tudo sem levar nada a sério. (p.19)

Travaglia (1990) afirma que o humor tem uma função a mais que apenas provocar o riso ele é capaz de ser usado como forma de denunciar, criticar e apontar algo que está errado. Como, por exemplo, a charges que são produzidas com o 
objetivo de denunciar ou criticar algo que a sociedade está enfrentando. A forma que o humor se apresenta é de maneira "mascarada".

O humor é uma atividade ou faculdade humana cuja importância se deduz de sua enorme presença e disseminação em todas as áreas da vida humana, com funções que ultrapassam o simples fazer rir. Ele é uma espécie de arma de denúncia, de instrumento de manutenção do equilíbrio social e psicológico; uma forma de revelar e de flagrar outras possibilidades de visão do mundo e das realidades naturais ou culturais que nos cercam e, assim, de desmontar falsos equilíbrios. (p.55).

Além disso, o discurso humorístico também pode ser utilizado com o objetivo de fazer algo sério transforma-se em algo aparentemente leve. Também sendo utilizado como uma forma de disfarçar os medos e para criticarem os problemas sociais vigentes, este tipo de discurso também é usada como uma maneira de amenizar ou disfarçar os discursos preconceituosos do sujeito que o reproduz. O discurso do humor é construído sem a devida preocupação com os sentimentos dos demais indivíduos, como apontado por Vale (2015), "O humor é por natureza ofensivo é despido de emoções fraternas, é humilhante para quem é o alvo do riso." (p.73).

O discurso humorístico pode ser encontrado materializado nos mais diversos gêneros discursivos ${ }^{1}$, assim como nas mais diversas mídias sociais, mas é no gênero piada que estes discursos são encontrados com facilidade. $\mathrm{O}$ gênero discursivo piada é uma forma pela qual um sujeito que deseja criticar ou humilhar se utiliza para divulgar seus ideais através do humor. A piada é um gênero do discursivo, por se constituir como uma atividade enunciativa que apresenta em si ideologias em sua constituição e através dela torna-se possível a produção de sentidos.

Devido utilizar como base para sua produção os problemas sociais ou polêmicos, o gênero torna-se um material de grande valor para o pesquisador que trabalha em AD. Como afirmado por Possenti (2005), "[...] as piadas só podem ocorrer num solo fértil de problemas, [...] solos cultivados durante séculos de disputas e de preconceitos.” (p.37). As análises das piadas fornecem para o pesquisador em $\mathrm{AD}$ algumas informações como, por exemplo, as condições para sua produção, ambiente em que elas circulam, os estereótipos mais utilizados em sua formulação, os sentidos que são produzidos, as FDs nelas presentes e os discursos que são produzidos.

Em nosso convívio social pode-se perceber diversos núcleos sociais como a família, escola, amigos entre outros. Com o advento da grande diversidade destes núcleos, eles acabam por serem constituídos por diversos pensamentos ideológicos relacionados ao gênero, trabalho, religião, etc. Alguns sujeitos, sem perceber, acabam tendo que aceitar tais pensamentos e através do discurso tendo que os promover, são pessoas que influenciados pelos discursos construídos socialmente acabam os reproduzindo sem questionar o motivo. São através do discurso, que se materializam as ideologias existentes na sociedade, como apontado por Brandão (2012), "O discurso é uma das instâncias em que a materialidade ideológica se concretiza, isto é, é um dos aspectos materiais da "existência material" das ideologias." (p.46).

O estereótipo refere-se às construções sociais com base em um modelo pré-estabelecido pela sociedade ligada, por exemplo, aos padrões de beleza, vestimentas e comportamentais. Segundo Vale (2012) "Trata-se de um domínio referencial que, preexistindo ao acontecimento discursivo, é por este atualizado e cristalizado sempre que resgatado.” (p.74). Os estereótipos estão presentes nos mais diversos gêneros textuais e são utilizados como formas de disseminarem algum tipo de padrão de pensamento ou de beleza com base em um valor pré-estabelecido socialmente. Podemos perceber a presença dos estereótipos em diversos gêneros discursivos, com o objetivo de difundi-los socialmente os fazendo estar presente durante a vida do indivíduo, com a finalidade de que todos possam ter esses estereótipos fixos em sua mente ao ponto de serem reproduzidos em algum momento. Conforme Vale (2012),

\footnotetext{
${ }^{1}$ A definição de gêneros discursivos, utilizado neste trabalho, se baseia na definição de Fiorin (2017) ao afirmar que "Os gêneros são tipos de enunciados relativamente estáveis, caracterizados por um conteúdo temático, uma construção composicional e um estilo.” (p.68-69)
} 
Disseminados através de alguns gêneros discursivos - placas de para-choque de caminhão, letras de música, charges, piadas -, os quais se encarregam de transmitir de geração a geração o conteúdo dos mesmos, passam, assim, a fazer parte do conhecimento coletivo de uma sociedade, armazenados na memória discursiva ou interdiscurso. (p.81).

Além disso, a existência do estereótipo está intimamente ligada ao preconceito, o que significa que para o surgimento de estereótipo é necessário que a sociedade possua algum preconceito. Os discursos preconceituosos, muitas vezes, encontramse construídos de tal forma que se faz necessário reconstituir os efeitos de sentido possíveis através daquilo que é efetivamente enunciado. Pode-se perceber, então, que este tipo de discurso não pertence a uma única voz, mas nela presente outras vozes em seu interior. Como apontado por Vale (2012), "O discurso preconceituoso materializado nos estereótipos, estes camuflados no discurso humorístico [...], não é falado por uma única voz, mas por muitas vozes, geradores de muitos discursos que se entrecruzam na materialidade do texto." (p.82). Portanto, o discurso humorístico, funciona baseado em estereótipos que estão presentes na sociedade para conseguirem produzir o riso. O estereótipo está atrelado ao preconceito que o sujeito defende, como apontado Rocha (2018) ao comentar sobre Marinho (2007),

Estereótipo e preconceito estabelecem entre si uma dialética "biunívoca". É impossível pensar um estereótipo sem preconceito e é impossível pensar um preconceito sem estereótipo. Um alimenta o outro. De fato, o estereótipo se origina de algum tipo de preconceito, que precisa criar imagens e conceitos - forçosamente errôneos porque carentes de fundamentos justos - que confiram um desvalor ao grupo que dele sofre, para justificar o próprio preconceito e as ações concretas dele decorrentes (ao que chamo discriminação). (p.54).

O estereótipo e o preconceito estão ligados de tal forma que se torna impossível pensar em um e sem perceber a presença do outro. No momento em que um estereótipo passa a ser difundido socialmente ele tem como base um preconceito presente na sociedade sobre algo que é considerado errado ou inaceitável.

Logo, os discursos empregados pela mídia ainda procuram difundir uma identidade para a mulher, uma imagem de que ela deve ser perfeita, segundo os ideais machistas. Observamos este tipo de estereótipo em propagandas em que as mulheres são mostradas segundo um padrão de beleza e sensualidade inatingível e que desconsideram as demais mulheres que não se encaixam neste modelo. Conforme Pereira (2018), "A imagem feminina, nos mais variados tipos de gêneros midiáticos, continua expressando estereótipos nos quais a mulher, mais do que nunca, é sujeita às exigências da juventude e da sedução." (p.109).

Contudo, através do discurso humorístico, a mulher é representada baseada nos estereótipos mais difundidos pela sociedade como, por exemplo, que a mulher seja uma espécie de monstro que domina a sua casa, de que elas são interesseiras e, para isso, utilizam da sensualidade feminina e o sexo para conseguir alcançar seus objetivos. Os estereótipos estão ligados à construção cultural brasileira e a construção às avessas das identidades, como apontado por Vale (2012), "Tais identidades, recorrentes no humor brasileiro, são percebidas como uma construção da nossa cultura.” (p.78).

\section{Identidade Feminina e os Estudos de Gênero}

Os estereótipos ligados à mulher têm a sua origem ligada ao passado da humanidade e às primeiras sociedades em que a mulher, durante muito tempo, foi enxergada como uma pessoa fadada a se tornar uma esposa exemplar que tomasse conta da casa, do marido e de seus filhos. Eram valores baseados em princípios patriarcais, por consequência machista. Valores esses que se apoiavam em interpretações religiosas de textos bíblicos que enxergavam a mulher como um ser submisso aos homens as quais não possuíam nem voz, nem vez na sociedade. Durante muitos séculos as mulheres procuravam se imporem contra estes ideais que eram reproduzidos socialmente, procurando se envolverem no mercado de trabalho e na política. 
Enfim, os anos 60 foram de grande destaque e importância para o mundo por causa dos movimentos sociais, como as revoltas estudantis, movimento hippie e outros ocorridos 1968, com o objetivo de lutar por uma melhoria em sua vida e pela igualdade. Outro fato também importante para década foi a respeito dos questionamentos referentes à sexualidade, como a questão da virgindade, gravidez e o prazer relacionado ao ato sexual. Um dos movimentos sociais que se destacaram e ganharam forças, até hoje perduram, são o movimento feminista e o movimento gay devido a ambos questionarem as relações nos sentidos afetivo-sexuais.

Esses movimentos também repercutiram no campo acadêmico, dando origem ao estudo de gêneros, surgindo entre 1970 e 1980, iniciando seus estudos sobre a condição da mulher. Os estudos realizados procuravam mostrar que as mulheres das classes trabalhadoras eram mais oprimidas que as outras, mas também levando-se em consideração de que isso se estendida para outras mulheres, independentemente da classe social, isso ocorria pelo fato de que a sociedade em que viviam sustentava a ideologia patriarcal. Em 1980, o foco se volta para os estudos sobre as mulheres, no qual era levado em consideração o fato de existir uma grande variedade de condições que as mulheres eram submetidas mundialmente em decorrência das diferenças regionais, idade, classes sociais.

Entretanto, mesmo que os estudos relacionados ao gênero tenham avançado sempre foi e ainda é polêmico, no que se refere aos papéis e importância social assumidos pelos indivíduos. Conforme Grossi (2000) "Gênero serve, portanto, para determinar tudo que é social, cultural e historicamente determinado." (p.5). Esse fato ocorre em decorrência da ideologia sustentada pelas sociedades que são firmadas pelo patriarcado, que desde a infância, objetiva ensinar as crianças desde cedo que as mulheres deverão se tornar donas de casa. Por exemplo, desde a infância são atribuídas às meninas brincadeiras e brinquedos que serviram para treinamento e preparação para o futuro que a reserva.

Essa diferenciação entre homens e mulheres, desde a infância até a idade adulta, também é utilizada para caracterizar as relações sociais entre eles, para diferenciar as pessoas e sua importância social. Isso ocorre desde os primórdios da humanidade em que vemos no ocidente, os trabalhos domésticos e menos dignos são geralmente atribuídos às mulheres. Sua importância e voz, na sociedade, foram sempre de papel secundário, fazendo com que elas fossem enxergadas apenas como genitoras e donas de casa, que segundo Grossi (2000),

[...] Joan Scott (1998), em recente definição da categoria gênero, ensina-nos que o gênero é uma categoria historicamente determinada que não apenas se constrói sobre a diferença de sexos, mas, sobretudo, uma categoria que serve para "dar sentido" a esta diferença. Concordo com essas definições e penso que, em linhas gerais, gênero é uma categoria usada para pensar as relações sociais que envolvem homens e mulheres, relações historicamente determinadas e expressas pelos diferentes discursos sociais sobre a diferença sexual. (p.5)

Tomemos como exemplo pela busca da exaltação da figura masculina, uma construção social que ficou enraizada na memória de todos é a questão de que o Homem com H maiúsculo é utilizado para se referir a toda humanidade como afirmado por Grossi (2000), “[...] Sempre aprendemos que Homem com H maiúsculo se refere à humanidade como um todo, incluindo nela homens e mulheres." (p.4). Algo que pode ser enxergado sem muita relevância, mas é, de fato, de suma importância, pois podemos verificar como a ideia de que os indivíduos do sexo masculino são considerados mais importantes mundialmente. Outro fato também relacionado aos homens é o do reforço da ideia da masculinidade, o macho mais macho. Tomamos, por exemplo o ator, apresentador e modelo Rodrigo Hilbert casado com Fernanda Lima, que ganham destaque nas redes sociais ganhando título de "homão da porra". Essa qualificação foi atribuída a ele devido ao programa no qual ele é o apresentador "Tempero da Família", exibido pelo canal GNT, onde ele demonstra seus talentos culinários, de construtor, de reformador e costureiro, procurando reforçar a ideia de que o homem deve procurar sobrepor os seus talentos, e condição masculina sobre os demais homens. 
Outra questão que, ao longo dos séculos, tornou-se um grande tabu e ainda perdura nos dias de hoje é referente ao prazer feminino na realização do ato sexual, que ainda é visto como algo pecaminoso e errado, pois segundo o discurso cristãoreligioso a finalidade do sexo é para reprodução humana. O homem possui o dever e o direito de sentir prazer e de se satisfazer sexualmente, porém a mulher não possui esse mesmo direito. Segundo Grossi (2000),

O prazer feminino era percebido como perigoso e patológico, sendo que passividade e frigidez eram considerados comportamentos femininos "naturais", portanto ideais. Hoje, com as inúmeras contribuições da Psicanálise e dos movimentos de libertação das mulheres, o desejo e o orgasmo femininos não são mais vistos como pecaminosos ou "antinaturais". (p.10)

Podemos perceber isso quando alguém comenta a respeito de um homem desde cedo se tornou ativo sexualmente passa a ser defendido com base no simples argumento dele ser homem, mas se a mulher decidir fazer a mesma coisa passa a ser vista como vulgar ou indecente. Este tipo de ideologia estar fundamentada em ideais constituídos pela própria sociedade que são reproduzidos continuamente, mas com advento dos movimentos sociais realizados pelos grupos feministas este tipo de discurso machista tem sido combatido e utilizado na formulação do discurso feminista acerca do empoderamento.

O discurso feminista de empoderamento tem ganhado cada vez mais força, fornecendo as condições de produção necessárias para produção de diversos gêneros discursivos. Uma forma utilizada para trabalhar este tipo de discurso é através dos programas humorísticos cujas piadas tipicamente são produzidas com base em ideais machistas, mas que foram produzidas com base em ideais feministas nas piadas pertencentes ao programa "Zorra”, como veremos adiante na análise.

\section{Descontruindo Estereótipos: Análise das Piadas}

A televisão e seus programas se constituíram, ao longo dos anos, como uma grande forma de entretenimento de massa e também como propagadores de ideologias. Recentemente, alguns programas têm passado por mudanças, adaptando-se aos novos tipos de telespectadores e suas exigências. Como o objetivo dos programas de entretenimento é distrair e divertir o telespectador, um dos gêneros mais procurados por eles possuem cunho humorístico, o qual foi escolhido para ser trabalhado nesta pesquisa.

O programa se firmou como um clássico da comédia do canal Globo durante os anos 2000, por apresentar personagens fixos e piadas que eram formuladas com base em estereótipos. Porém, o programa foi reformulado em 2015, apresentando grandes mudanças desde o cenário que não estava mais preso a apenas estúdios da rede Globo de televisão, os quadros que começaram a ser baseado em situações do cotidiano. $\mathrm{O}$ conteúdo das piadas tornou-se mais crítico relacionadas à política, a sociedade e os papéis sociais nelas representados. A reformulação teve como objetivo as transformações sociais vigentes que estão se firmando. O programa adotou em seus quadros a representação do discurso um humorístico voltado para questionamentos e críticas sociais². O que, conforme, Gruda (2011),

[...] o discurso humorístico de alguns meios, por carregar em seu bojo o questionamento e a crítica às práticas e costumes sérios e oficiais da sociedade, das instituições, etc. e assim conseguir virar isto tudo do avesso, como um discurso que pode provocar reflexões. (p.757)

Trataremos, então, a respeito da primeira piada.

\footnotetext{
${ }^{2}$ Em dezembro de 2020, “Zorra" saiu da programação da emissora. Mas o site oficial do humorístico continua online com episódios e esquetes vistas na TV.
} 
Piada 1: Posso passar a mão?

Um homem passeando com seu cachorro de estimação. De repente uma mulher loira aparece e fala: - Ai! Eu não aguento! Posso passar a mão? O dono do cachorro logo responde - Claro!

A mulher bate nas nádegas dele, e exclama:

- “Ah é! Oh lá em casa!”.

Fonte: GSHOW: Zorra.

A piada intitulada "Posso passar a mão?" é construída com base em uma cena comum que pode ocorrer diariamente uma pessoa que está passeando com seu animal de estimação. O humor desta piada advém da quebra de expectativa que é produzida: primeiramente se pressupunha que a mulher falava do animal de estimação, e não do dono, em segundo plano, ocorreu uma inversão dos papéis dos sujeitos, pois geralmente neste tipo de humor popular a mulher é que é assediada, não o contrário. Ocorre uma evidente inversão de papéis, que causa um estranhamento na personagem, e, eventualmente, nos telespectadores.

Observa-se que a piada foi construída levando em consideração a experiência criminosa pela qual as mulheres cotidianamente passam, a do assédio sexual. Esse tipo de piada crítica só se tornou possível através da posição social que as mulheres assumiram com o advento das manifestações realizadas pelos movimentos feministas, pois quando eram assediadas tinham que se calar mediante esses atos. Muitas mulheres no ambiente de trabalho passavam e ainda passam por este tipo ato criminoso e por medo de perderem o emprego e de serem mal faladas pela sociedade se calam, mas devido aos inúmeros protestos realizados contra esse tipo de ato, hoje elas são defendidas e protegidas por lei, mas mesmo assim a violência não diminuiu.

No enunciado Ah é! Oh lá em casa!, é possível perceber a presença do interdiscurso definido por Orlandi (1999) como “[...] todo o conjunto de formulações feitas e já esquecidas que determinam o que dizemos.” (p.33), pelo fato desse enunciado em destaque ter como base um enunciado muito utilizado na prática do assédio sexual. Através do interdiscurso um conjunto de formulações é esquecido e acaba por determinar os enunciados que serão reformulados no futuro filiado com a memória discursiva. Ao ouvir tal enunciado, nos é retomada a memória que esse enunciado é muito recorrente e associado popularmente a uma prática masculina, machista e misógina, frequente em diversos espaços sociais.

A piada é produzida no interior de uma da Formação Discursiva em que circulam discursos machistas, objetivando-se produzir um sentido de crítica e denúncia a esse tipo de prática. Só se tornando possível em decorrência do momento sóciohistórico e da posição social conquistada pelas mulheres atualmente de se impor contra o machismo. Segundo Fernandes e Sá (2021), "Uma formação discursiva resulta de um campo de configurações que coloca em emergência os dizeres e os sujeitos socialmente organizados em um momento histórico específico.” (p.62). Muitas denúncias são realizadas em decorrência a este tipo de crime, os quais eles se defendem com base no argumento de que são as próprias mulheres que os provocam ao ponto de realizarem este tipo de atitude. Essa espécie de discurso também é utilizada por estupradores.

As ações tomadas pelo movimento feminista têm garantido à mulher voz e apoio para lutar contra o ato criminoso do assédio sexual que muitas mulheres sofreram seja na rua ou no mercado de trabalho. Muitos casos foram divulgados com relação a esse ato a fim de despertar nas demais mulheres o sentimento de luta contra esse tipo de atitude. Mas, infelizmente este crime continua crescendo. O feminismo também tem como objetivo de produzir nas mulheres o desejo de se impor socialmente, tornando-se empoderadas, como pode ser observado na piada a seguir. 
Piada 2: Princesas empoderadas

Os sete anões estão ao redor de Branca de Neve que esta deitada, aparentemente morta. O príncipe vem se aproximando a fim de beijá-la, mas Branca de neve desperta apertando um dispositivo spray de pimenta na cara do príncipe. Então ela grita:

- Ah! Sai! Que isso cara?! Vem tão perto quando a gente tá dormindo!

Nesse momento o príncipe sai gritando. Ela olha em direção ao príncipe em fuga e diz:

-Sai de perto da minha vida! Pronto acordei. (Olhando para os anões)

-Não vou lavar mini cueca de ninguém. Tão felizes?!

\section{Fonte: GSHOW: Zorra.}

A piada "Princesas empoderadas" utiliza-se da memória discursiva referente ao conto de fadas infantil, Branca de Neve. A cena retrata o momento que os anões a colocam em um caixão de cristal, em um determinado dia um príncipe a vê e se apaixona dando nela um beijo apaixonado, o que a faz desperta. Ele se casa com ela e juntos vivem felizes para sempre, o que não ocorreu na piada. A memória discursiva referente ao conto não é despertada pelo enunciado era uma vez que é mais comum nas produções baseadas em contos de fadas, mas nesse caso ela é realizada pelo uso da figuração dos atores que retoma a memória do telespectador que se trata do conto Branca de Neve. Esse conto geralmente é trabalhado com as crianças em particular para as do sexo feminino, a fim de as ensinarem e as prepararem para que, no futuro, encontrem um homem que venha se tornar um príncipe encantado que a ajude a se livrar dos problemas e dificuldades. Ela então necessita vir a se tornar uma boa "princesa" se comportando como uma esposa ideal se preparando para ser obediente para com o seu marido e futuros filhos. Porém, na piada, é possível perceber, então, uma desconstrução desse ideal no momento que a personagem rejeita não só o beijo como o príncipe.

A quebra da expectativa do telespectador, mediante a cena, deve-se ao fato de que foram levadas em consideração as condições de produção atuais a respeito dos movimentos feministas e a respeito do empoderamento feminino. A ideologia relacionada à mulher ser frágil e dependente da figura masculina para resolver seus problemas assim, como aceitarem as imposições por ele estabelecidas é totalmente desconstruída pelo discurso humorístico interpelado com o discurso feminista. O humor se constitui na piada pelo fato de que quem conhece o conto esperava que a personagem tivesse o mesmo fim que a original, mas quando Branca de Neve desperta, ela quebra com os sentidos socialmente construído e reproduzido para ela.

O discurso da personagem, em análise, é produzido numa FD só se torna possível através dos movimentos sociais das mulheres com relação ao empoderamento feminino. Mas, ao mesmo tempo, em que esse tipo de discurso ocorre ele acaba entrando em conflito com as FDs nas quais se apoiam discursos machistas e os contos de fadas. Conforme Fernandes e Sá (2021), "Como formação discursiva reflete, também, formação social, retoma-se uma heterogeneidade própria à coexistência e “miscigenação" das diferentes forças sociais." (p.63). A enunciação é constituída pelas lutas que levam em questão que a mulher não necessita de um homem para ser feliz, nem viver em dependência de uma figura masculina ou seguindo as suas ordens.

O enunciado Vem tão perto quando a gente tá dormindo!, retoma o ato de dormir que é uma necessidade física e nesse momento o ser humano torna-se indefeso. Este enunciado retoma então o estereótipo que não só a mulher é frágil, mas também o homem e que ambos necessitam de alguém para os proteger. Mas, a ação realizada pela personagem quebra com essa fragilidade no momento em que o príncipe encantado deseja lhe roubar um beijo ela se defende com um spray de pimenta, uma ferramenta voltada para o uso das mulheres que procuram se defender contra criminosos que atentam sobre sua vida.

Ao enunciar Não vou lavar mini cueca de ninguém., a personagem se impõe contra a ideologia de que a mulher deve obedecer sem questionamentos ou imposições às ordens masculinas, retomando, também, os sentidos sobre o papel doméstico da mulher: lavar, passar, cozinhar para o marido. 
Este enunciado poderia ser considerado uma resposta referente a uma ordem feita a ela, o que não é o caso. A personagem utilizou-se deste enunciado para evidenciar que por mais que ela não tenha aceitado o príncipe não significava que ela ficaria com um dos anões. Nesta piada, o efeito de sentido produzido é de uma desconstrução referente aos papéis estabelecidos socialmente de subserviência atribuídos à mulher. Produz-se o sentido de que a mulher pode ser independente $\mathrm{e}$ impor seus ideais na sociedade sem depender da figura masculina para isso.

Piada 3: Famosinha do motel.

Um casal chega ao motel. E o recepcionista fala para a cliente:

-Oh Claudinha! Como é que tá? Beleza?

Ela responde:

-Hum... beleza você pode pegar a chave do quarto...

$\mathrm{O}$ recepcionista a interrompe dizendo:

-212, sei que cê acha lindo! Tá na mão.

O recepcionista entrega a chave e o casal saem dando um beijo, ao se aproximar da porta Claudinha é surpreendida por um cliente do motel, que diz:

- Aé Claudinha bem acompanhada!

Ela com vergonha responde:

-He, eu vou fechar a porta aqui.

O cliente logo responde:

-Se joga Claudinha!

Claudinha, apreensiva, procura se justificar ao namorado dizendo:

- Olha deixa eu te explicar uma coisa, calma aí um minuto.

O namorado logo a interrompe:

- Que isso linda?! Poxa! 2019 daí que você já veio aqui com outros caras uma, duas, cinco, dez vezes.

Claudinha, então, responde:

-Não, não, é que não deu tempo de te falar uma coisa...

O namorado a interrompe mais uma vez, dizendo:

-Relaxa, sei lá, eu sou um cara moderno. Você ser uma mulher livre me deixa mais interessado. Sabia?

Claudinha espantada logo responde:

- Sério?!

A faxineira do motel bate na porta e pergunta à Claudinha:

- Foi mal, você sabe onde está o aspirador de pó?

Claudinha rapidamente responde:

- Esqueci ontem lá no armário do almoxarifado, agora, deixa eu curtir minha folga em paz.

Fonte: GSHOW: Zorra.

A piada 3 acunhada por "Famosinha do motel" mostra uma cena cotidiana em motéis, a chegada de um casal para usufruir das instalações do estabelecimento. O humor desta piada provém rompimento da expectativa do público que até o momento supunha que a personagem Claudinha era uma mulher livre com fama de namoradora. A construção do enredo, presente na piada, possuía como objetivo produzir o sentido de que a personagem era alguém que tinha grande familiaridade com aquele estabelecimento em particular por possuir uma vida sexual ativa, mas a quebra desse sentido que estava sendo construído ocorre no momento em que a personagem enuncia: Esqueci ontem lá no armário do almoxarifado, agora deixa eu curtir minha folga em paz., revelando então que ela era funcionária do motel.

O namorado de Claudinha faz a seguinte enunciação Que isso linda?! Poxa! 2019 daí que você já veio aqui com outros caras uma, duas, cinco, dez vezes., esse enunciado só pode ser possível em vista da posição social que as mulheres alcançaram com relação à liberdade sexual. Essa posição hoje assumida pela mulher, por muitos anos, não era possível e ainda não é bem aceita pela sociedade com base em um discurso religioso de que a mulher só poderia ter relações sexuais ao se casar e que a prática sexual só teria que ter como objetivo a mulher engravidar. O discurso religioso procura impor a mulher o papel 
de dona de casa subserviente aos desejos e vontades do marido, por tanto elas só poderiam ter uma vida sexual ao casar e se caso decidisse ter relações sexuais antes do casamento seria vista como prostituta.

O enunciado Relaxa, sei lá, eu sou um cara moderno. Você ser uma mulher livre me deixa mais interessado. Sabia?, se apoia numa FD em que a mulher tem a liberdade de namorar e ter relações sexuais. A enunciação realizada pelo namorado surpreendeu Claudinha, pois ela supunha que ele teria realizado uma má interpretação do que falaram sobre ela e que a rejeitaria. O indivíduo que enunciou foi interpelado pelo discurso e ideologia a respeito da liberdade sexual da mulher, o que possibilitou a produção desse tipo de enunciado. Diferentemente dos personagens masculinos presentes nas demais piadas analisadas, este personagem se destaca por enunciar a partir de outra formação discursiva, na qual não só reconhece como também admite que a liberdade sexual feminina a torna mais interessante. Conforme Brandão (2012),

O conceito de formação discursiva norteia a referência à interpelação/assujeitamento do indivíduo em sujeito do seu discurso[...]. Definido como "o que pode e deve ser dito por um sujeito", esse conceito possibilita o fato de que sujeitos falantes, tomados em uma conjuntura histórica determinada, possam concordar ou se afrontar sobre o sentido a dar às palavras. $(\mathrm{p} 77)$

A posição assumida pelo personagem só foi possível devido ao sujeito ter sido interpelado pelos discursos feministas que estão circulando socialmente. Mas, no momento em que ele decide assumir esta posição ideológica ele também se apega ao estereótipo de que mulher que possui liberdade sexual deve ser dominada pelo homem. Tomemos como exemplo a prática criminosa do estupro corretivo, realizado por homens que acreditam que mulheres lésbicas devem violentadas a fim de serem corrigidas mediante a sua orientação sexual. Os ideais feministas têm, priori, a instauração de direitos igualitários para homens e mulheres como poder frequentar diversos ambientes, antes vetados a elas. Como poderemos observar no texto seguinte.

\section{Piada 4: Mulher no barbeiro.}

Alguns homens estão conversando no interior de uma barbearia, então chega uma mulher. O que causa certa estranheza no ambiente. Ela olha para o barbeiro e diz:

- Licença. Tudo bom, moço? Eu queria só cortar dois dedinhos, só dois dedinhos. Porque luzes ressecam demais o cabelo. Não dá!

$\mathrm{O}$ barbeiro responde

- Opa! Desculpa. A senhora sabe que aqui é uma barbearia, não é um salão de beleza não é?

A mulher reponde ao barbeiro, dizendo:

Sim, eu sei uma barbearia, por isso que eu vim pra cá. Tem jogo, tem bar. Amor, salão de beleza só tem

fofoca, pelo amor de Deus. Inclusive eu posso tomar uma cerveja? Ele, prontamente responde-a:

Claro!

Ela feliz exclama:

Eba! Que joia! Tudo bem gente? Algum problema?

A mulher começa observar três homens conversando enquanto jogam sinuca. Então o primeiro fala: -

Como eu tava falando, tu viu que o Marquinho tá pegando a Bruna?

O segundo homem pergunta para os outros dois:

- A Bruna? Perdão, mas ela não pegava o Mariola?

O terceiro homem responde:

- O Mariola já deve estar sabendo, eu fui ver, não se seguem mais.

Fonte: GSHOW: Zorra.

A piada 4 "Mulher no barbeiro" trouxe como cenário para realização do humor uma barbearia, um ambiente com foco para o público masculino que oferece além de corte de cabelo e barba, oferece o serviço de bar. A construção do humor ocorre no momento em que uma mulher chega a um ambiente popularmente masculino, para conseguir a realização dos serviços por ela desejados, serviços esses que são prestados em salões de beleza. 
A situação narrada na piada que retrata uma mulher entrando em uma barbearia só pode ser possível por causa da desconstrução dos papéis sociais atribuídos a mulher assim como dos direitos que só eram permitidos aos homens como, por exemplo, frequentar os mesmos ambientes. Por muito tempo, alguns ambientes eram considerados estritamente masculinos, sendo proibida e vedada as mulheres frequentarem o mesmo ambiente que eles, como neste caso a barbearia. Como no enunciado realizado pelo barbeiro ao ouvir o pedido feito pela mulher em seu estabelecimento comercial Opa! Desculpa. A senhora sabe que aqui é uma barbearia, não é um salão de beleza não é?. O barbeiro a questionou não só a respeito do pedido feito com relação ao cabelo, mas, em seu enunciado, é perceptível a presença de outras vozes masculinas que estão incomodados com a presença da mulher naquele estabelecimento.

Ao realizar tal enunciação o barbeiro é interpelado em sujeito pelo discurso machista de separação de ambientes femininos e masculinos. Fernandes e Sá (2021) afirma que "A voz desse sujeito revela o lugar social; logo, expressa um conjunto de outras vozes integrantes de dada realidade histórica e social; de sua voz ecoam as vozes constitutivas e/ou integrantes desse lugar sócio-histórico.” (p.36).

É possível observar essas outras vozes constituídas no discurso no enunciado Inclusive eu posso tomar uma cerveja? Nele estão presentes as vozes das mulheres que lutaram para ter a liberdade de realizar ações enquadradas como masculino. $\mathrm{O}$ enunciado foi formulado com base nas condições de produção que levam em conta o momento sócio-histórico conquistado pela mulher. Conforme Fernandes e Sá (2021) “As transformações sofridas nas condições sociais manifestam-se nas produções discursivas, sempre marcadas pelo entrecruzamento de discursos e acontecimentos anteriores.” (p.37). Esse contexto sóciohistórico possibilita que a FD empregada pelo sujeito possa ser realizado considerado o momento sócio-histórico no qual o personagem estar inserido, o que para Brandão (2012), "são as formações discursivas que, em uma formação ideológica específica e levando em conta uma relação de classe, determinam "o que pode e deve ser dito" a partir de uma posição dada em uma conjuntura dada."(p.48).

No enunciado produzido pela mulher traz a seguinte informação Sim, eu sei uma barbearia, por isso que eu vim pra cá. Tem jogo, tem bar. Amor salão de beleza só tem fofoca, pelo amor de Deus., o enunciado retoma o estereótipo de que a mulher é fofoqueira e como um salão de beleza é um ambiente geralmente frequentado por mulheres o que produzirá o sentido de que neste tipo de estabelecimento onde mais se realiza essa prática. Mas, a personagem ao ouvir os demais homens falando descobre que a fofoca também ocorre em ambientes masculinos.

Mesmo com os novos padrões humorísticos voltados para crítica social alguns programas de humor têm dado continuidade à proposta humorística que apresentavam desde a sua estreia na televisão, por exemplo, o programa "A Praça é Nossa". O humorístico é exibido atualmente pelo canal aberto SBT (Sistema Brasileiro de Televisão), que desde 1987 tem procurando apresentar sempre uma atualização dos personagens. O programa realizou várias trocas de personagens, porém estilo do humor politicamente incorreto vem permanecendo sempre o mesmo, cheio de estereótipos.

Historicamente, os papéis atribuídos aos homens são o de ser provedor da casa e o chefe da família e às mulheres o de ser a dona de casa. Mas, após as manifestações realizadas pelo movimento feminista, as mulheres conseguiram então romper com este ideal e demonstrar que as coisas não são tão fixas como é imposto. O discurso realizado pelo personagem apresenta em seu interior as vozes dos homens que se contrapõe aos ideais feministas. A piada é produzida no interior de uma da FD em que circulam discursos machistas e feministas, com o objetivo produzir um sentido de não aceitação das mudanças de papéis sociais assumidos por homens e mulheres.

\section{Conclusão}

Como afirma Silva (2016), os estereótipos são formas de pressupostos linguísticos-discursivos socialmente padronizados e que se constituem culturalmente. Em geral, se materializam nas diferentes formas da expressão humorística. 
Assim, ideologias foram estabelecidas com relação ao funcionamento da sociedade, uma das mais antigas foi o machismo. Essa ideologia foi reproduzida através dos mais diversos discursos, a exemplo do humor, que se perpetuaram ao longo dos séculos. Mas, com advento das transformações sociais que vêm se estabelecendo ao longo da história da humanidade, provocou-se, então, uma transformação ideológica que tem sido refletida na construção e desconstrução dos sujeitos, pois os mesmos tornam-se (re)produtores dos discursos que circulam socialmente.

Mesmo que o discurso do humor utilizado pelos programas televisivos tenha se consagrado por serem constituído por preconceitos e estereótipos, os quais são reproduzidos, um novo discurso humorístico voltado para crítica tem emergido. Percebemos ao realizarmos as análises das piadas exibidas pelo programa "Zorra", no qual é apresentada uma proposta de problematizar, fazer refletir e realizar uma desconstrução dos estereótipos que serviram como base histórica para construção de uma identidade feminina. Os discursos presentes nas piadas são produzidos com base em uma FD machista com a finalidade de construir sentidos e FD feministas.

O sujeito discursivo está sempre em construção, pois o mesmo é interpelado por diversos discursos e diversas vozes sociais que estão em conflitos, assim como também a identidade é construída socialmente. Conforme Fernandes e Sá (2021) "A identidade, assim como o sujeito, não é fixa, está sempre em produção, encontra-se em um processo interrupto de construção e é caracterizada por mutações." (p.31).

As piadas veiculadas no programa "Zorra" são fundamentadas em situações cotidianas, o conteúdo tematiza a mulher com a proposta de se produzir uma quebra dos sentidos relacionados aquilo que é imposto socialmente como o papel da mulher ou algum estereótipo direcionado a este sujeito. Verificou-se que os textos em análise tinham como base a memória discursiva relacionada aos papéis sociais atribuídos à mulher de ser dona de casa e esposa obediente, assim como os estereótipos de que a ex-mulher é barraqueira, relacionada ao assédio sexual que elas sofrem ser ter direito a se imporem contra este tipo de ação, e a liberdade sexual feminina ou de frequentar ambientes que durante muito tempo eram tipicamente masculinos.

A partir do que foi comentado a respeito da base teórica utilizada neste artigo e as análises nele presentes, podemos afirmar que as piadas veiculadas no programa humorístico "Zorra" cujo objeto discursivo é a mulher contribuem para desconstruir os estereótipos sobre estes sujeitos que haviam sido construídas com base em discursos machistas, comumente reproduzidos por este gênero de entretenimento televisivo. Mas, também percebemos que ao desfazer um estereótipo ele acaba gerando ou confirmando outros como no caso das piadas "Famosinha do Motel" e "Mulher no barbeiro", em que acabam reforçando o estereótipo sobre a mulher fofoqueira e que a mulher livre deve ser dominada.

As piadas utilizaram dos discursos machistas que são reproduzidos socialmente, com a finalidade de desconstruir tais ideais. Compreendemos que a partir dos discursos que são vinculados nas mídias a mulher é levada a um estado de contínua construção e desconstrução de sua identidade.

\section{Referências}

Bortoni-Ricardo, S. M. (2008). O professor pesquisador: introdução à pesquisa qualitativa. São Paulo: Parábola. 135p. (Série Estratégias de Ensino, n. 8.).

Brandão, H. H. N. (2012). Introdução à análise do discurso. (3a ed) Editora da Unicamp.

Bezerra, C. T. P., \& Domingos, J. (2017). Memória discursiva e interdiscursividade: um diálogo entre gerações na (des)construção da Amélia. Discursividades. Revista do Depto de Letras e Artes da UEPB., (1). 23- 42.

Fernandes, C. A., \& Sá, I. (2021). Análise do Discurso - reflexões introdutórias. Pontes editores.

Fiorin, J. L. (2017). Introdução ao pensamento de Bakhtin. Contexto.

Freitas, G. C. (2011). Entendendo a piada: uma análise linguística.

Grossi, M. P. (2000). Identidade de Gênero e Sexualidade. Estudos de Gênero - Cadernos de Area 9, Goiânia, 9, 9-46.

Gruda, M. P. P. (2011). Uma Análise do Discurso do Humor. Travessias (UNIOESTE. Online), 5, 747-760. 
Research, Society and Development, v. 10, n. 14, e227101422564, 2021

(CC BY 4.0) | ISSN 2525-3409 | DOI: http://dx.doi.org/10.33448/rsd-v10i14.22564

Joanilho, A. L., \& Joanilho, M. P. G. (2012). Enunciado e discurso em Michel Foucault. Língua e instrumentos Linguísticos, 1. 27-41.

Màziere, F. (2007). A análise do discurso. Parábola Editorial.

Minois, G. (2003). História do riso e do escárnio. Tradução de Maria Elena O. Ortiz Assumpção. UNESP.

Orlandi, E. P. (1999). Análise de discurso-Princípios \& Procedimentos. Pontes.

Orlandi, E. P. (2010). Introdução a ciência da linguagem: discurso e textualidade. (2a ed.) Pontes editores.

Atti, A. R. (2012). A noção de sujeito discursivo. Fragmentum (UFSM), 1, 18-21.

Pereira, A. S., et al. (2018). Metodologia da pesquisa científica. UFSM.

Pereira, T. M. A. (2017). O corpo da mulher en(cena) no espetáculo da publicidade. Discursividades. Revista do Depto de Letras e Artes da UEPB. Campina Grande-PB, 2. 97- 122.

Possenti, S. (2005). Os humores da língua: análises linguísticas de piadas. (4a ed.) Mercado de Letras.

Rocha, E. M. A (2018). (Re)produção do estereótipo nas piadas: sobre os sentidos do humor. Discursividades. Revista do Depto de Letras e Artes da UEPB. 3. 48- 64 .

Schneiders, C. M., \& Klein, M. S. (2019). Efeitos do ideológico e do histórico nos discursos em circulação. In: Caderno de Linguagem e Sociedade, 20 (1). p. 201-219.

Silva, P. C. D. (2016). Utilização dos programas de estereótipo da figura do humor na tv brasileira: uma análise linguístico-discursiva sobre os efeitos do senso de humor no gênero humorístico. Pesquisa, Sociedade e Desenvolvimento, 3 (1), 55-68.

Simões JR, A. C. (2004). Memória e discurso: "O lampião da esquina" e a construção da identidade homossexual. In: VIII Congresso Nacional de Lingüística e Filologia, 2004, Rio de Janeiro. Cadernos do CNLF, 5.

Travaglia, L. C. (1990). Uma introdução ao estudo do humor pela linguística. D.E.L.T.A, 6(1), 55-82.

Vale, A. R. O. (2012). Estereótipos na publicidade mascarados no discurso humorístico: HOPE ensina. In: Leandro, M. L. S., Aranha S. D. G., \& Pereira, T. M. A. (orgs.). Os sentidos (des)velados pela linguagem. Ideia, 73-93.

Vale, A. R. O. (2015). "Bichas": a construção da identidade do sujeito homoerótico no discurso humorístico. In.: Silva, P. D. S. (org.) Escrit@s sobre gênero e sexualidades. Scortecci, 71-82.

\section{Endereços eletrônicos}

A praça é nossa. (2017). Sangue reclama de ter que lavar louça. https://www.youtube.com/watch?v=8XS7zQQ8Wiw.

Gshow: zorra. (2019). Mulher no barbeiro. https://gshow.globo.com/programas/zorra/2019/episodio/2019/06/01/videos-do-episodio-dezorra-de-sabado-01-dejunho.ghtml\#video-7661780-id.

Gshow: zorra. (2019). Famosinha do motel. https://gshow.globo.com/programas/zorra/2019/episodio/2019/06/29/videos-do-episodio-dezorra-de-sabado-29de-junho.ghtml\#video-7730162-id.

Gshow: zorra. (2018). Posso passar a mão? https://gshow.globo.com/programas/zorra/2018/episodio/2018/07/21/videos-de-zorra-desabado-21-dejulho.ghtml\#video-6889319-id

Gshow: zorra. (2018). Princesas empoderadas.https://gshow.globo.com/programas/zorra/2017/episodio/2018/01/13/videos-de-zorra-desabado-13-dejaneiro.ghtml\#video-6420867-id 